\title{
Fault plane of the 1964 Niigata earthquake, Japan, derived from relocation of the mainshock and aftershocks by using the modified joint hypocenter determination and grid search methods
}

\author{
Nobuo Hurukawa ${ }^{1}$ and Tomoya Harada ${ }^{2,3}$ \\ ${ }^{1}$ Building Research Institute, Tsukuba, Ibaraki 305-0802, Japan \\ ${ }^{2}$ Center for Integrated Disaster Information Research, Interfaculty Initiative in Information Studies, The University of Tokyo, Tokyo, Japan \\ ${ }^{3}$ Earthquake Research Institute, The University of Tokyo, Tokyo, Japan
}

(Received March 11, 2013; Revised June 21, 2013; Accepted June 22, 2013; Online published December 6, 2013)

\begin{abstract}
We relocated the mainshock and immediate aftershocks of the 1964 Niigata earthquake $\left(M_{\mathrm{S}} 7.5\right)$ using both the modified joint hypocenter determination (MJHD), and the grid search (GS), methods to obtain their hypocenters and identify the fault plane of the mainshock. We used $P$-wave arrival times at 13 Japanese stations reported by the Japan Meteorological Agency (JMA). Firstly, we performed the MJHD method to select readings with high accuracies and to obtain station corrections that related to the lateral heterogeneity of the Earth's structure. Secondly, we performed the GS method by using only selected readings and assuming the station corrections. Based on the relocated hypocenters, we found that the mainshock and immediate aftershocks occurred along a plane striking $\mathrm{N} 15^{\circ} \mathrm{E}$ and dipping $11^{\circ}$ eastward. This result strongly suggests that one of the nodal planes of the mainshock, for which the strike and dip are $\mathrm{N} 9^{\circ} \mathrm{E}$ and $34^{\circ}$, respectively, is preferable as the fault plane. When global stations are also used for relocations, the results confirm that the fault plane of the 1964 Niigata earthquake dips gently eastward. Therefore, we concluded that the fault plane of the 1964 Niigata earthquake is gently eastward-dipping.
\end{abstract}

Key words: Niigata earthquake, fault plane, modified joint hypocenter determination method, grid search method, aftershock.

\section{Introduction}

The Niigata earthquake $\left(M_{\mathrm{s}} 7.5\right)$ of June 16,1964 , occurred to the south of Awashima Island, Niigata Prefecture, in central Japan. It was a thrust earthquake located at the eastern margin of the Japan Sea mobile belt that extends from Sakhalin to off Niigata (e.g., Ohtake et al., 2002). The southern end of the belt connects to the Itoigawa-Shizuoka tectonic line and is considered to constitute a section of the convergent boundary between the Eurasian and North American plates (Kobayashi, 1983; Nakamura, 1983). Nakamura (1983) proposed the existence of a nascent trench along the eastern Japan Sea (Fig. 1). Large earthquakes, including the 1983 Nihon-Kai Chubu earthquake (Japan Sea earthquake, $M_{\mathrm{w}}$ 7.7) and the 1993 SW off Hokkaido earthquake $\left(M_{\mathrm{w}} 7.7\right)$, have occurred east of the nascent trench along the eastern Japan Sea (Fig. 1). The fault plane of the 1983 Nihon-Kai Chubu earthquake is gently eastward-dipping, as ascertained from the distribution of aftershocks (e.g., Umino et al., 1985). This is consistent with the subduction of the Eurasian Plate at the nascent trench along the eastern Japan Sea. However, the fault plane of the 1993 SW off Hokkaido earthquake is westward-dipping at the southern part of the source area and

Copyright (c) The Society of Geomagnetism and Earth, Planetary and Space Sciences (SGEPSS); The Seismological Society of Japan; The Volcanological Society of Japan; The Geodetic Society of Japan; The Japanese Society for Planetary Sciences; TERRAPUB.

doi:10.5047/eps.2013.06.007 eastward-dipping at the northern part (e.g., Tanioka et al., 1995). The complex nature of the fault planes might reflect the fact that this is a new plate boundary where subduction has just started.

The 1964 Niigata earthquake, which occurred to the south of these earthquakes, is a reverse fault earthquake with an E-W compressional axis (Hirasawa, 1965; Aki, $1966 \mathrm{a}, \mathrm{b})$. There have been various studies of the fault plane of the earthquake using different kinds of geophysical data, and both westward-dipping and eastward-dipping fault plane models have been proposed. Vertical and horizontal crustal movements on land have been explained by a westward-dipping fault plane model with a steep angle (Abe, 1975; Matuhashi et al., 1987), while a vertical crustal movement at the ocean bottom has been explained by a gently eastward-dipping fault plane model (Satake and Abe, 1983). Although aftershocks have been relocated to obtain the fault plane of the mainshock, it is very difficult to identify the fault plane because of the poor determination accuracy of hypocenters (Kayano, 1968; Hamada, 1983; Fujiwara and Seno, 1985; Mori and Boyd, 1985; Kusano and Hamada, 1991). Using a Bayes method for temporary observations of aftershocks, Kayano and Imoto (1989) concluded that hypocenters were distributed along the eastdipping fault plane rather than along the west-dipping one, based on the Akaike Bayes Information Criteria (ABIC).

The fault plane of a large earthquake is one of most fundamental pieces of seismological information required to 


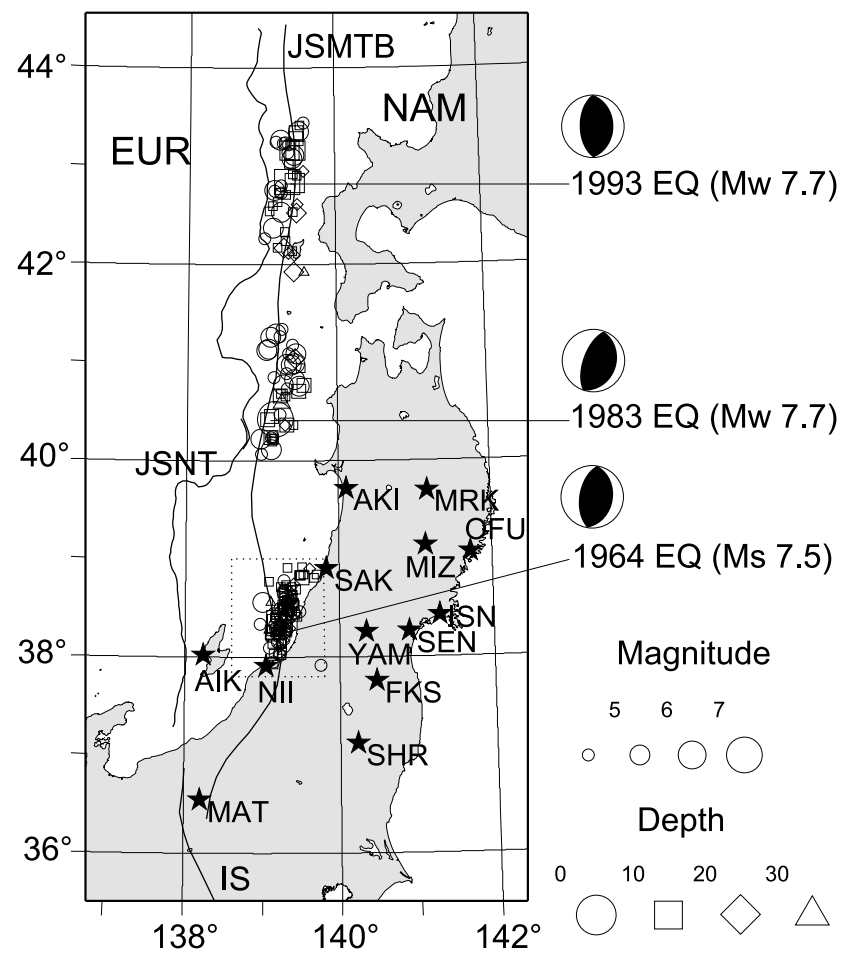

Fig. 1. Major tectonic lines and the distribution of stations in the study area. Stars indicate the stations used in this study. Aftershocks of the 1964 Niigata (this study), and of the 1983 Nihon-Kai Chubu and 1993 SW off Hokkaido earthquakes (Hurukawa, 2011), are also shown. Symbols and sizes of symbols differ according to depths and magnitudes of earthquakes, respectively. Focal mechanisms of the Niigata earthquake (Abe, 1975) and other events by Global CMT solutions (Dziewonski et al. (1981) and later updates) are also shown. JSNT: Nascent Trench along the eastern Japan Sea proposed by Nakamura (1983). JSMTB: Main tectonic boundary along the eastern Japan Sea (Taira, 2002). IS: Itoigawa-Shizuoka tectonic line. EUR: Eurasian Plate. NAM: North American Plate.

understand the mechanism of the occurrence of the earthquake and the seismo-tectonics of the source area, as well as for evaluating the prospect of future earthquakes. The source area of the Niigata earthquake is located at the main tectonic boundary of the eastern margin of the Japan Sea (Taira, 2002). Seismic gaps, in which large earthquakes are expected to occur in the near future, exist in areas adjacent to the Niigata earthquake (Ohtake, 2002). To evaluate the potential occurrence of future earthquakes and their source mechanisms, the fault plane of the Niigata earthquake should be identified as accurately as possible.

In this study, both the modified joint hypocenter determination (MJHD) and the grid search (GS) methods are used to relocate the hypocenters of the 1964 Niigata earthquake and its immediate aftershocks by using the arrival times of $P$ waves at stations reported by the Japan Meteorological Agency (JMA). We then identify the preferred fault plane of the mainshock.

\section{Methods and Data}

To accurately relocate hypocenters, we employed the modified joint hypocenter determination (MJHD) method developed by Hurukawa and Imoto (1990, 1992). Because of the lateral heterogeneity of the Earth's structure, the assumption of a horizontally homogeneous velocity model, as normally used in standard hypocenter determinations, is inadequate for obtaining accurate locations of earthquakes. The joint hypocenter determination (JHD) method (Douglas, 1967; Freedman, 1967; Dewey, 1972) enables us to simultaneously relocate many earthquakes, thereby removing the effects of lateral heterogeneity. In doing so, we define a station correction that accounts for the lateral heterogeneity of structure. JHD solutions may, however, become unstable and unreliable as a result of the trade-off between station corrections and estimated focal depths, given the heterogeneous nature of the Earth's structure and the problems that arise from poor station coverage. For this reason, Hurukawa and Imoto $(1990,1992)$ developed the MJHD method for locating local earthquakes, in which the station correction is independent of both the distance and azimuth from the center of the studied region to the given station, thereby improving the stability of the method. Subsequently, Hurukawa (1995) extended the MJHD method for locating teleseismic earthquakes, and we use this extended version in this study.

Locations by the MJHD method, however, might depend on the initial hypocenters assumed. Therefore, we also used a grid search (GS) method to analyze the data. Assuming a hypocenter at many grid points and different origin times for each earthquake, we calculated theoretical travel times for stations. Then, the sum of squares of travel-time residuals (SSR in $\mathrm{s}^{2}$ ) at all grid points were calculated and compared. The grid point with the minimum SSR was identified as the hypocenter of the earthquake. However, there are two big problems in the GS method. These are: (1) effects related to the lateral heterogeneity of the Earth's structure; and (2) selection of good reading data. We overcame these problems by the joint use of the MJHD and the GS methods. That is: (1) to apply station corrections obtained by the MJHD method to remove the effects of the lateral heterogeneity; and (2) to use only readings finally used in the MJHD method after examining readings to select readings with high accuracies. Standard errors of the GS solution were given by the square root of the diagonal elements of the variance-covariance matrix for hypocentral parameters (e.g. Havskov and Ottemöller, 2010).

We obtained hypocenters and phase arrival data from the Japan Meteorological Agency (JMA), and analyzed them for the period June 16-30, 1964. Events were selected at all depths within the region $37.8^{\circ}-39.0^{\circ} \mathrm{N}, 138.6^{\circ}-$ $139.8^{\circ} \mathrm{E}$ (dotted areas in Figs. 1-4). Figure 2(a) shows JMA hypocenters of 469 earthquakes in the study area for the period of interest.

Only $P$-wave arrival times were used in this study, because these are more reliably observed than are the subsequent $S$-wave and later-phase arrival times. Although direct $S$ waves observed at stations close to the source region would help to constrain the hypocenter depths, it would be very difficult to judge whether an initial $S$ wave at each station for each event is a direct wave, or a diffracted wave, without examining seismograms. Therefore, we preferred to use only initial $P$ waves. We used the iasp91 model (Kennett and Engdahl, 1991) to estimate travel times. 

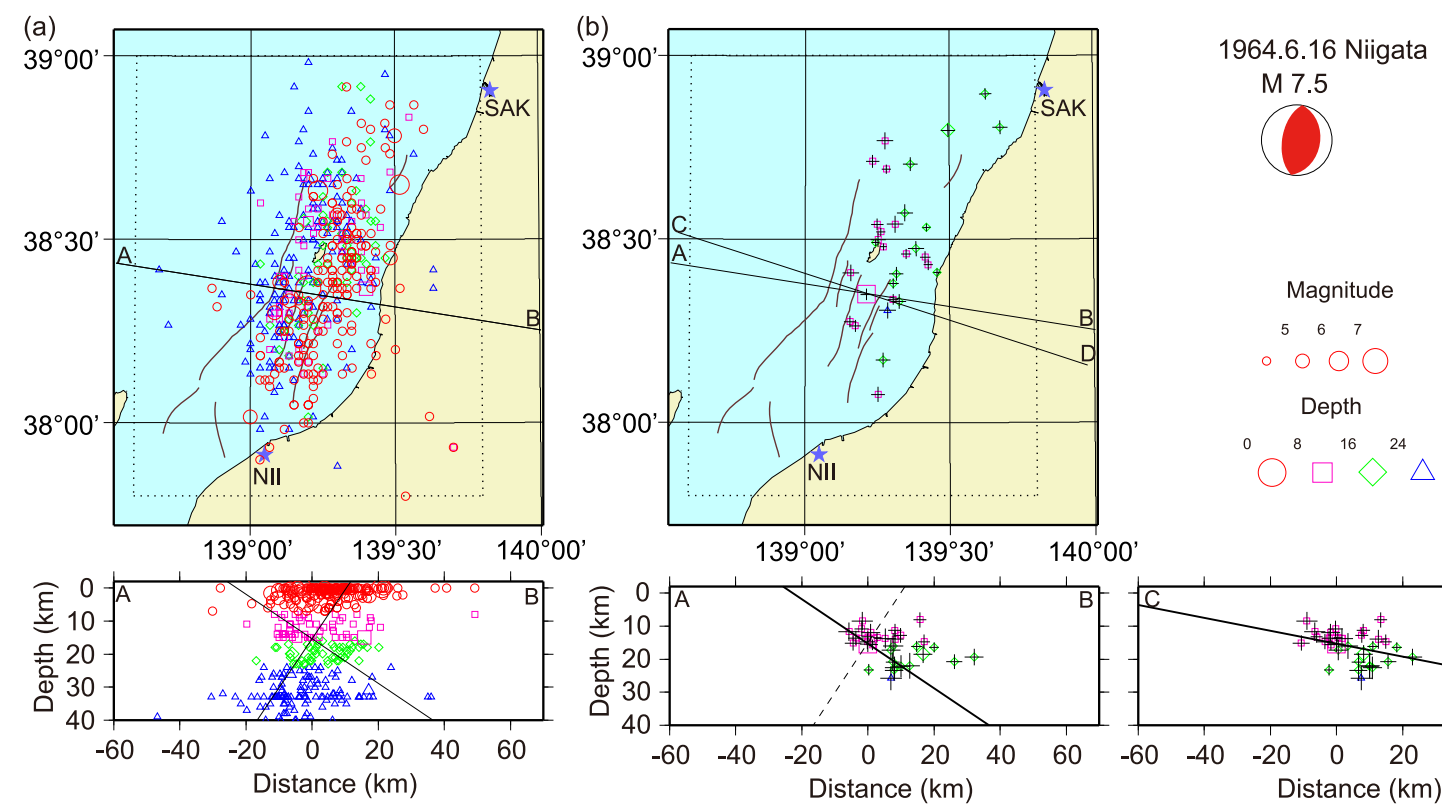

Fig. 2. Comparison of the aftershock distribution using JMA data with the mainshock focal mechanism estimated by Abe (1975). (a) JMA locations. (b) Hypocenters relocated by using the MJHD method. Strike A-B is perpendicular to the strikes of the two nodal planes estimated by Abe (1975), while strike C-D is parallel to the dip-direction of the best-fit plane. The solid and broken lines in the depth section A-B denote the two nodal planes of the focal mechanism that pass through the hypocenter of the mainshock. The sizes of the crosses denote the error bars of the relocated hypocenters. Solid lines represent the surface traces of active anticline axes as established by Okamura et al. (1994).

\section{Results of the MJHD Method}

To improve the locational accuracy, it is essential to select stations at which many earthquakes have been observed with a high precision, and then to use only precise readings at these stations for hypocenter determination. On such a basis, we selected five important nearby JMA stations (NII, SAK, AIK, FUK, and AKI in Fig. 1), for which Kusano and Hamada (1991) had carefully re-picked arrival times. In addition, we selected additional stations in the following preliminary analysis. We relocated the hypocenters of 131 earthquakes assuming that the minimum number of stations (MSTN) that observed each earthquake was 10 and the minimum number of events (MEVN) observed at each station was 40 . During the relocation process, readings with arrival-time residuals exceeding $2 \mathrm{~s}$ were identified and then excluded from further analysis. The number of stations used in the analysis was 23 , including the five aforementioned stations. The number of earthquakes used at each station varied from 41 to 124 . If we chose stations that recorded smaller numbers of events together with those that recorded many events, a bias of hypocenter locations might be introduced between earthquakes that were recorded by the smaller-number stations and those that were not. Therefore, we selected only those stations that recorded a large number of events.

Two stations, NII and SAK, located on opposite sides of the source area, contributed highly-precise hypocenter locations. The number of earthquakes recorded and used at SAK was 73 and was the least for the five above-mentioned stations, which were re-examined by Kusano and Hamada (1991). Therefore, for the subsequent final analyses we selected only the 13 stations, for which the epicentral distances were less than $2.1^{\circ}$, which recorded at least 73 events, as shown in Fig. 1.
Following Kusano and Hamada (1991), who re-examined and analyzed arrival times at JMA stations, we used readings with travel-time residuals of $<1.5 \mathrm{~s}$. Here, MSTN and MEVN were set to 12 and 30, respectively, to locate 36 events. Figure 2(b) shows the 31 relocated hypocenters of the mainshock and aftershocks for which the standard errors of latitude, longitude, and focal depth are $<0.03^{\circ},<0.03^{\circ}$, and $<5 \mathrm{~km}$, respectively. Thirteen stations were used (see Fig. 1). The cross-section A-B in Fig. 2(b) shows the two nodal planes of Model II estimated by Abe (1975). The strike of the planes is $\mathrm{N} 9^{\circ} \mathrm{E}$ and the westward-dipping plane dips at $56^{\circ}$ while the eastward-dipping plane dips at $34^{\circ}$. It is clear that the relocated hypocenters are distributed not along the steeper westward-dipping nodal plane, but along the gentler eastward-dipping plane.

We also obtained a best-fit plane for the 3-D hypocenter distribution using the least-squares method. The direction of maximum dip is $\mathrm{E} 18^{\circ} \mathrm{S}$ and the dip is $11^{\circ}$. The crosssection C-D in Fig. 2(b) shows a vertical projection of the hypocenters in this direction. Since the hypocenters contain large errors, it is pointless to discuss the above values in detail. However, the result confirms that the eastward dipping nodal plane is preferable as the fault plane of the $1964 \mathrm{Ni}$ igata earthquake.

\section{Results of the Grid Search Method}

We examined the 36 final hypocenters determined with the MJHD method by using the grid search (GS) method. Applying the station corrections obtained in the MJHD method, we used only the readings finally used in the MJHD method, which had travel-time residuals of $<1.5 \mathrm{~s}$. The GS method was performed in several steps. In the first step, grids covered the range of $\pm 10.0 \mathrm{~s}$ in origin time, $\pm 1.0^{\circ}$ in longitude and latitude, and $\pm 50 \mathrm{~km}$ in depth from the fi- 


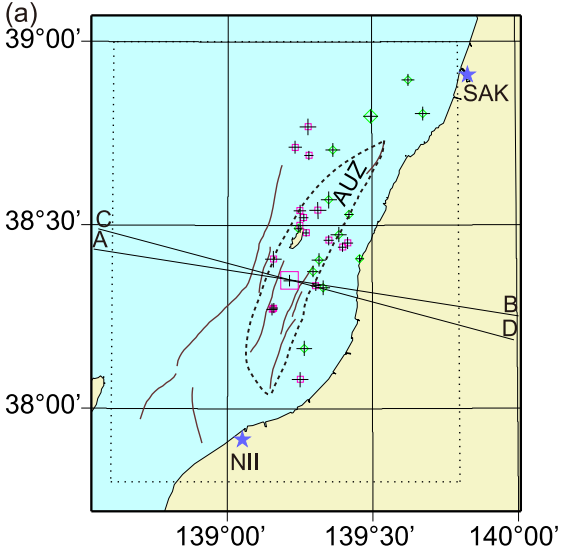

1964.6.16 Niigata M 7.5
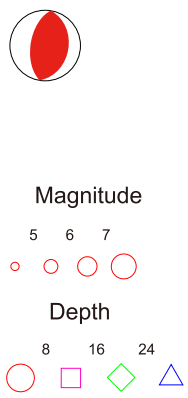

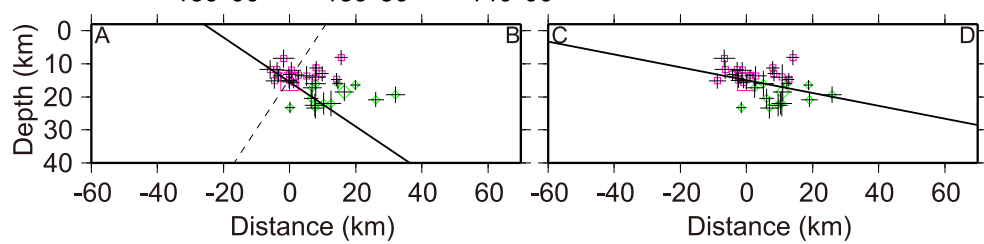

(b)
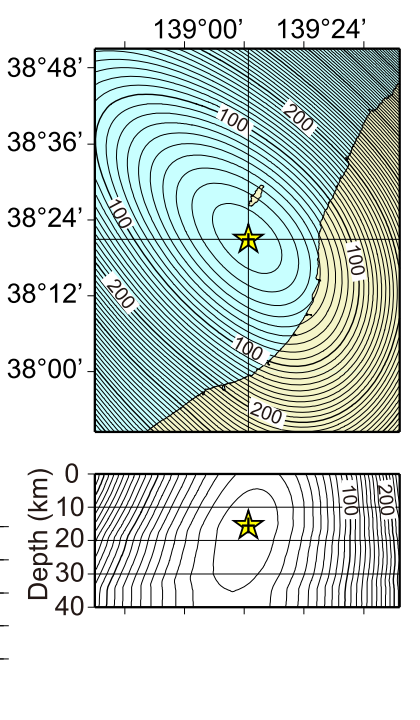

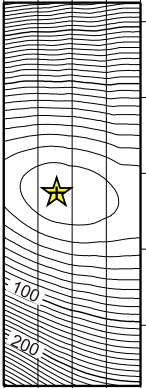

010203040 Depth $(\mathrm{km})$

Fig. 3. Relocated hypocenters using JMA data performed by the GS method. (a) Final hypocenters relocated by using the GS method. The Awashima Uplift Zone (AUZ) is shown by a thick broken line. Symbols are the same as those in Fig. 2. (b) Distribution of the sum of squares of residuals (SSR in $\mathrm{s}^{2}$ ) for the mainshock calculated by using the GS method.
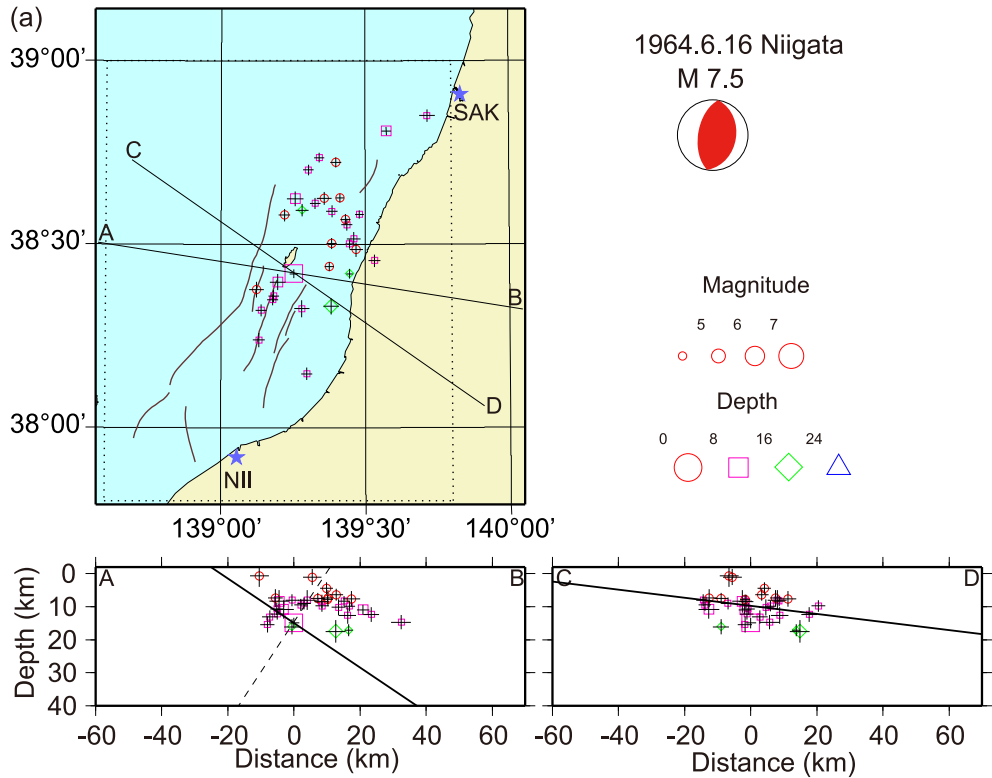

(b)
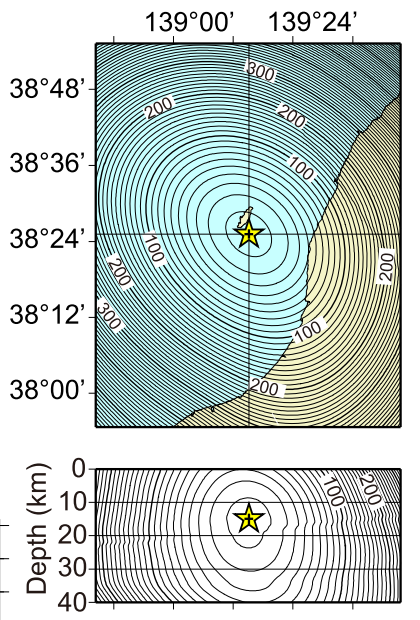

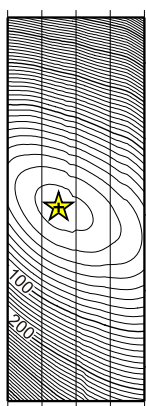

10203040 Depth $(\mathrm{km})$

Fig. 4. Relocated hypocenters using both JMA and ISC data performed by the GS method. (a) Hypocenters relocated by using the GS method. Symbols are the same as those in Fig. 2. (b) Distribution of the sum of squares of residuals (SSR) for the mainshock calculated by using the GS method.

nal hypocenter in the MJHD method. The grid interval was then reduced to $1.0 \mathrm{~s}, 0.1^{\circ}$, and $10.0 \mathrm{~km}$, respectively. The grid interval for the final search was $0.01 \mathrm{~s}, 0.01^{\circ}$, and 0.1 $\mathrm{km}$, respectively.

Figure 3(a) shows the 30 relocated hypocenters of the mainshock and aftershocks for which the standard errors of latitude, longitude, and focal depth were $<0.03^{\circ},<0.03^{\circ}$, and $<5 \mathrm{~km}$, respectively.

Averages and standard deviations of differences (between values generated by the MJHD and the GS methods) for the 30 hypocenters are $0.000^{\circ} \pm 0.003^{\circ}$ for latitudes, $0.002^{\circ} \pm 0.007^{\circ}$ for longitudes and $-0.04 \pm 0.22 \mathrm{~km}$ for focal depths. These differences are smaller than the minimum grid intervals of the GS method and are much smaller than the standard errors of the MJHD and GS hypocenters. This result demonstrated that MJHD solutions did not trap in the local minimums of the SSRs, i.e., did not significantly depend on the initial hypocenters.

We obtained a best-fit plane for the 3-D hypocenter distribution using the least-squares method. The direction of maximum dip is $\mathrm{E} 15^{\circ} \mathrm{S}$ and the dip is $11^{\circ}$. The cross-section C-D in Fig. 3(a) shows a vertical projection of the hypocenters in this direction. Therefore, we conclude that the fault plane of the 1964 Niigata earthquake corresponds to the eastward-dipping nodal plane.

Figure 3(b) shows the 3-D distribution of SSRs (sum of 
squares of travel-time residuals) for the mainshock. The longwise SSR contours on the vertical cross-section along longitude clearly show the poorly-constrained nature of the mainshock focal depth. The contours, moreover, lean to the west. Since the SSR distributions of the immediate aftershocks show the same feature, it may be that the scattering of hypocenters due to poorly-constrained focal depths produces the westward- and steeply dipping distribution of mainshock and aftershocks.

\section{Discussion}

\subsection{Combination of JMA and ISC data for relocation}

Distant stations, where seismic rays are near vertical, contribute mainly to the determination of focal depths. For example, in the case of a focal depth of $10 \mathrm{~km}$, partial derivatives of travel times with respect to epicentral distance and focal depth, $d T / d \Delta$ and $d T / d Z$, respectively, are as follows: $d T / d \Delta$ at stations with $\Delta=1^{\circ}$ and $100^{\circ}$ are 13.98 and $4.44 \mathrm{~s} /$ degree, respectively, while $d T / d Z$ at stations with $\Delta=1^{\circ}$ and $100^{\circ}$ are 0.016 and $-0.168 \mathrm{~s} / \mathrm{km}$, respectively. The latter value, $-0.168 \mathrm{~s} / \mathrm{km}$ at $\Delta=100^{\circ}$, is very close to the value of $0.172 \mathrm{~s} / \mathrm{km}$ at a station with $\Delta=0^{\circ}$ with opposite sign. That is, phase data at distant stations contribute to focal depths but not to epicenters.

Therefore, in order to confirm the results in Sections 3 and 4 where we used only JMA data, we relocated earthquakes using JMA data and additional International Seismological Centre (ISC) data outside of Japan. The time period and area used were the same as those described in Section 2. Since ISC data include only a small number of JMA stations, while JMA bulletins include all data at JMA stations, including revised readings by Kusano and Hamada (1991), we used readings at JMA stations reported by the JMA bulletins instead of those provided by the ISC. We used only 13 JMA stations, the same as those used for the analysis in Sections 3 and 4. We relocated earthquakes by setting values for MNST at 14 and MEVN at 25. During the relocation process, readings with arrival-time residuals exceeding $2.0 \mathrm{~s}$ were identified and excluded from the analysis. Forty-two earthquakes were relocated using the 25 stations including the 13 JMA stations. When we used the original MJHD method for global locations, as proposed by Hurukawa (1995), the focal depths of many earthquakes became $0 \mathrm{~km}$, which represents an artificial bias. This bias was mainly caused by the difference between the assumed velocity model and the actual velocity structure. Since the effect of the difference is the same for all the earthquakes, relative locations are still reliable. To remove this artificial bias related to focal depths, Hurukawa et al. (2008) introduced a new parameter $a_{1}$, which can shift a group of earthquakes vertically. The larger the $a_{1}$ is, the deeper the calculated focal depths are. Therefore, we set $a_{1}=0.4$ here, because no earthquakes were located at $0 \mathrm{~km}$ in depth when $a_{1} \geq 0.4$.

Assuming the station corrections obtained in the MJHD method and using only readings that were finally used in the MJHD method, in which travel-time residuals were $<2.0 \mathrm{~s}$, we performed the GS method. Figure 4(a) shows the 34 relocated hypocenters of the mainshock and aftershocks for which the standard errors of latitude, longitude, and focal depth are $<0.03^{\circ},<0.03^{\circ}$, and $<5 \mathrm{~km}$, respectively. The cross-section A-B in Fig. 4 shows the two nodal planes of Model II estimated by Abe (1975).

We also obtained a best-fit plane to the 3-D hypocenter distribution using the least-squares method. The direction of maximum dip is E28 $\mathrm{S}$ with a dip of $8^{\circ}$. The crosssection C-D in Fig. 4(a) shows a vertical projection of the hypocenters in this direction. The plane is very similar to the plane obtained in Section 4. Therefore, this confirms that the fault plane of the 1964 Niigata earthquake corresponds to the eastward-dipping nodal plane.

Figure 4(b) shows the 3-D distribution of SSR for the mainshock determined using both JMA and ISC stations. It is clear that intervals of SSR contours in the depth direction are equivalent to those in the E-W direction, indicating that the incorporation of ISC stations resulted in improved depth accuracies. The SSR distributions of immediate aftershocks have the same tendency as those of the mainshock.

\subsection{Comparison with previous studies}

Our main result of the eastward dipping for the Niigata earthquake confirms the finding of Mori and Boyd (1985), who relocated aftershocks using the joint hypocenter determination (JHD) method. They used 11 stations within an epicentral distance of $2^{\circ}$. Ten of those 11 stations were also used in the present study. However, the errors of hypocenters determined by Mori and Boyd (1985) were very large compared with those calculated here. The main reasons for this difference are that we were able to use readings at five stations re-examined by Kusano and Hamada (1991), and that we used only $P$-wave arrival times, which are much more accurate than $S$-wave arrival times.

Our result also corresponds with the finding of Kayano and Imoto (1989), who applied an algorithm for estimating the locations of earthquake clusters to select the most probable fault plane among several possible candidates (Imoto and Hurukawa, 1988) for aftershocks of the Niigata earthquake recorded by temporary observations (Kayano, 1968). Kayano and Imoto (1989) analyzed data from July 2 to 6 , 1964 , which is some two weeks after the mainshock, but we were able to analyze immediate aftershocks and found that they occurred on an east-dipping fault plane.

However, our result is in contrast to the finding of Kusano and Hamada (1991), who relocated hypocenters of aftershocks using the JHD method. They used 15 JMA stations including 12 of the stations that we used in our MJHD-GS relocation. The contrasting result is probably due to three reasons: (i) those authors located smaller earthquakes that were recorded at a smaller number of stations, since one of their main purposes was to locate as many earthquakes as possible; (ii) they used $S$-waves as well as $P$-waves in hypocenter determination; and (iii) they used three additional stations for which readings were less accurate than for our 13 selected stations. We conclude that, in order to obtain accurate aftershock distributions, it is important to select stations that record many earthquakes with a high degree of accuracy, and to use only accurate arrival times of the initial $P$-waves at the selected stations. The procedure that we used for station and data selection for the MJHD-GS method enabled us to relocate many earthquakes simultaneously and with a high degree of accuracy. 


\subsection{Comparison with the geological structure}

We also examined the absolute accuracy of relocated hypocenters by comparing our results with JMA hypocenters. We calculated the differences between the epicenters estimated using MJHD-GS (in which we used only JMA data, as in Section 3.1) and those using JMA (i.e., MJHDGS minus JMA) for the 30 earthquakes shown in Fig. 3(a). The average differences and their standard deviations are $-0.004^{\circ} \pm 0.040^{\circ}$ for latitudes, $0.018^{\circ} \pm 0.032^{\circ}$ for longitudes, and $-1.80 \mathrm{~km} \pm 13.35 \mathrm{~km}$ for focal depths, and there is no significant bias. Furthermore, we examined the absolute accuracy of focal depths by comparing our result with that of Kayano (1968), who made temporary observations of aftershocks. According to Kayano (1968), earthquakes during June 23 and 30 were concentrated between 5 and 20 $\mathrm{km}$ depth. Although hypocenters from the JMA and $\mathrm{Ku}-$ sano and Hamada (1991) were scattered from 0 to $40 \mathrm{~km}$ depth, focal depths of almost all earthquakes were relocated to depths shallower than $25 \mathrm{~km}$ using the MJHD-GS method in this study, and are similar to the focal depths determined by Kayano (1968).

On the basis of these results, it is possible to compare the MJHD-GS hypocenter distribution map with the geological structure in and around the source area. According to Okamura et al. (1994), and Okamura and Kato (2002), the aftershock area of the Niigata earthquake corresponds to the Awashima Uplift Zone (AUZ). The western part of the AUZ dips steeply and consists of anticlines cut by westwarddipping high-angle reverse faults. Therefore, if the fault that caused the Niigata earthquake had been a westward-dipping high-angle reverse fault, the mechanism of the earthquake would correspond to the active structure in the area. However, the result of the relocation of aftershocks in this study indicates that the fault plane dips eastward. In that case, the western edge of the aftershock area corresponds to the western edge of the AUZ and to active anticline axes in the western part of the AUZ (Fig. 3). Since the western extension of the Niigata earthquake fault would reach the active anticline axes at the surface, the Niigata earthquake fault might have a close relationship with these active anticlines.

Several $M \geq 7.5$ earthquakes have occurred along the eastern margin of the Japan Sea, including the 1964 Niigata earthquake and the 1983 Nihon-Kai Chubu earthquake. The discovery of a seismic gap off Akita prefecture between the source areas of the 1833 Shonai $(M 7.5)$ and the 1983 Nihon-Kai Chubu $\left(M_{\mathrm{w}} 7.7\right)$ earthquakes led Ohtake (1995, 2002) to propose the possibility of an $M \sim 7.5$ earthquake. In this study, we have been able to confirm that the fault plane of the 1964 Niigata earthquake dips eastward, similar to that of the 1983 Nihon-Kai Chubu earthquake. Since the western edges of these earthquakes were located near the main tectonic boundary along the eastern Japan Sea (JSMTB) (Fig. 1), the fault plane of a future earthquake will also likely dip gently eastward.

\section{Conclusion}

To identify the fault plane of the 1964 Niigata earthquake $\left(M_{\mathrm{s}} 7.5\right)$, we relocated the hypocenters of the June 16 mainshock and its aftershocks to June 30 using both the modified joint hypocenter determination (MJHD) and grid search (GS) methods. We used $P$-wave arrival times at 13 JMA stations. Firstly, the MJHD method was performed to select readings with high accuracies and to obtain station corrections. Secondly, applying the station corrections to selected readings, we performed the GS method. The mainshock and its aftershocks are distributed along the gently eastward-dipping plane. This result suggests that the preferable fault plane of the 1964 Niigata earthquake is the eastward-dipping nodal plane estimated by Abe (1975), which has a direction of maximum dip and a dip of $\mathrm{E} 9^{\circ} \mathrm{S}$ and $34^{\circ}$, respectively. We also relocated earthquakes using $P$-wave arrival times at 13 JMA stations and 12 global stations using the both MJHD and GS methods. The mainshock and its aftershocks are distributed along the eastwarddipping nodal plane, similar to the result using only JMA data.

Acknowledgments. We express our gratitude to Dr. N. Hamada, who provided valuable comments, and to the Japan Meteorological Agency (JMA), who provided us with the JMA readings. We thank two anonymous reviewers for their helpful comments on the manuscript.

\section{References}

Abe, K., Re-examination of the fault model for the Niigata earthquake of 1964, J. Phys. Earth, 23, 349-366, 1975.

Aki, K., Generation and propagation of $\mathrm{G}$ waves from the Niigata earthquake of June 16, 1964. Part 1. A statistical analysis, Bull. Earthq. Res Inst., 44, 23-72, 1966a.

Aki, K., Generation and propagation of $\mathrm{G}$ waves from the Niigata earthquake of June 16, 1964. Part 2. Estimation of earthquake moment, released energy, and stress-strain drop from the $\mathrm{G}$ wave spectrum, Bull. Earthq. Res. Inst., 44, 73-88, 1966b.

Dewey, J. W., Seismicity and tectonics of western Venezuela, Bull. Seismol. Soc. Am., 62, 1711-1751, 1972.

Douglas, A., Joint epicenter determination, Nature, 215, 47-48, 1967.

Dziewonski, A. M., T.-A. Chou, and J. H. Woodhouse, Determination of earthquake source parameters from waveform data for studies of global and regional seismicity, J. Geophys. Res., 86, 2825-2852, 1981.

Freedman, H. W., A statistical discussion of $\mathrm{P}$ residuals from explosions, Part 2, Bull. Seismol. Soc. Am., 57, 545-561, 1967.

Fujiwara, K. and T. Seno, Redetermination of the aftershock distribution of the 1964 Niigata earthquake, Zisin (J. Seismol. Soc. Jpn.), 38, 259-261, 1985.

Hamada, N., Re-examination of aftershock distribution of the Niigata earthquake in 1964, Zisin (J. Seismol. Soc. Jpn.), 36, 663-664, 1983.

Havskov, J. and L. Ottemöller, Routine Data Processing in Earthquake Seismology: With Sample Data, Exercises and Software, 347 pp., Springer Dordrecht Heidelberg London New York, 2010.

Hirasawa, T., Source mechanism of the Niigata earthquake of June 16, 1964, as derived from body waves, J. Phys. Earth, 13, 35-66, 1965.

Hurukawa, N., Quick aftershock relocation of the 1994 Shikotan earthquake and its fault planes, Geophys. Res. Lett., 22, 3159-3162, 1995.

Hurukawa, N., IISEE's aftershock distributions and corresponding fault planes, http://iisee.kenken.go.jp/cgi-bin/eqcatalog.newv6/ mjhdcatalog_eng.cgi, (ref. on 2011-9-1), 2011.

Hurukawa, N. and M. Imoto, Fine structure of an underground boundary between the Philippine Sea and Pacific plates beneath the Kanto district, Japan, Zisin (J. Seismol. Soc. Jpn.), 43, 413-429, 1990 (in Japanese with an English abstract).

Hurukawa, N. and M. Imoto, Subducting oceanic crust of the Philippine Sea and Pacific plates and weak-zone-normal compression in Kanto district, Japan, Geophys. J. Int., 109, 639-652, 1992.

Hurukawa, N., M. Popa, and M. Radulian, Relocation of larger intermediate-depth earthquakes of the Vrancea region, Romania, since 1934 and a seismic gap, Earth Planets Space, 60, 565-572, 2008.

Imoto, M. and N. Hurukawa, Determination of fault plane by aftershock distribution, Abstract for Ann. Meet. Seismol. Soc. Jpn., No. 2 C15, 1988 (in Japanese).

Kayano, I., Determination of origin times, epicenters and focal depths of 
aftershocks of the Niigata earthquake of June 16, 1964-a preliminary report of the cooperative study of aftershocks of the Niigata earthquake, Bull. Earthq. Res. Inst., 46, 223-269, 1968.

Kayano, I. and M. Imoto, Estimation of hypocenter distribution by means of Bayes method, Abstract for Ann. Meet. Seismol. Soc. Jpn., No. 2 C139, 1989.

Kennett, B. L. N. and E. R. Engdahl, Travel times for global earthquake location and phase association, Geophys. J. Int., 105, 429-465, 1991.

Kobayashi, Y., On the initiation of subduction of plates, Earth Monthly, $\mathbf{5}$, $510-514,1983$ (in Japanese).

Kusano, F. and N. Hamada, Re-investigation of hypocenter distribution of the 1964 Niigata earthquake and its aftershocks, Zisin (J. Seismol. Soc. $J p n.), 44,305-313,1991$ (in Japanese with an English abstract).

Matuhashi, Y., T. Aburakawa, and H. Sato, Horizontal displacements accompanied with the Niigata earthquake of 1964 and its fault model, Zisin (J. Seismol. Soc. Jpn.), 40, 619-622, 1987 (in Japanese with an English abstract).

Mori, J. and T. Boyd, Seismological evidence indicating rupture along an eastward dipping fault plane for the 1964 Niigata, Japan earthquake, $J$. Phys. Earth, 33, 227-240, 1985.

Nakamura, K., Possible nascent trench along the eastern Japan Sea as the convergent boundary between Eurasian and North American plates, Bull. Earthq. Res. Inst., 58, 711-722, 1983.

Ohtake, M., A seismic gap in the eastern margin of the Japan Sea as inferred from the time-space distribution of past seismicity, The Island Arc, 4, 156-165, 1995.

Ohtake, M., Earthquake potential in the eastern margin of Japan Sea, in Active Faults and Seismo-Tectonics in Eastern Margin of Japan Sea, edited by M. Ohtake, A. Taira, and Y. Ohta, 175-185, Uni. Tokyo Press, 2002 (in Japanese).

Ohtake, M., A. Taira, and Y. Ohta, Active Faults and Seismo-Tectonics in Eastern Margin of Japan Sea, Uni. Tokyo Press, 2002 (in Japanese).

Okamura, Y. and H. Kato, Tectonic relief and active faults in sea areas, in Active Faults and Seismo-Tectonics in Eastern Margin of Japan Sea, edited by M. Ohtake, A. Taira, and Y. Ohta, 47-69, Uni. Tokyo Press, 2002 (in Japanese).

Okamura, Y., M. Sato, and J. Miyazaki, Active faults and folds on the shelf off Niigata and their relation to the 1964 Niigata earthquake, Zisin (J. Seismol. Soc. Jpn.), 46, 413-423, 1994 (in Japanese with an English abstract).

Satake, K. and K. Abe, A fault model for the Niigata, Japan earthquake of June 16, 1964, J. Phys. Earth, 31, 217-223, 1983.

Taira, A., Tectonics in the eastern margin of Japan Sea and Japan Island, in Active Faults and Seismo-Tectonics in Eastern Margin of Japan Sea, edited by M. Ohtake, A. Taira, and Y. Ohta, 3-15, Uni. Tokyo Press, 2002 (in Japanese).

Tanioka, Y., K. Satake, and L. Ruff, Total analysis of the 1993 Hokkaido Nansei-Oki Earthquake using seismic wave, tsunami, and geodetic data, Geophys. Res. Lett., 22, 9-12, doi:10.1029/94GL02787, 1995.

Umino, N., A. Hasegawa, K. Obara, T. Matsuzawa, H. Shimizu, A. Takagi, K. Tanaka, and M. Kosuga, Hypocenter distribution of foreshocks and aftershocks of the 1983 Japan Sea earthquake, Zisin (J. Seismol. Soc. $J p n$.), 38, 399-410, 1985 (in Japanese with an English abstract).

N. Hurukawa (e-mail: hurukawa@kenken.go.jp) and T. Harada 